\title{
Differences in Rental and Nonrental Car Crashes
}

\author{
Richard Tay ${ }^{1}$ and Jaisung $\mathrm{Choi}^{2}$ \\ ${ }^{1}$ School of Business IT \& Logistics, RMIT University, Melbourne, VIC, Australia \\ ${ }^{2}$ Department of Transportation Engineering, University of Seoul, Seoul, Republic of Korea \\ Correspondence should be addressed to Richard Tay; rtay888@gmail.com
}

Received 20 March 2017; Revised 18 May 2017; Accepted 1 June 2017; Published 4 July 2017

Academic Editor: S. C. Wong

Copyright (C) 2017 Richard Tay and Jaisung Choi. This is an open access article distributed under the Creative Commons Attribution License, which permits unrestricted use, distribution, and reproduction in any medium, provided the original work is properly cited.

Although rental cars experience a higher collision rate per registered vehicle compared to nonrental cars, little research has been conducted to understand the differences in the factors contributing to crashes involving rental cars and nonrental cars, especially driver-related factors. This study develops a conceptual framework to compare the driver-related factors contributing to crashes involving rental cars and nonrental cars and tests the hypotheses developed using data from South Korea and applying the binary logistics, rare event logistics, Firth logistic models, and random parameters logit models. We found a significantly higher contribution of several risky driving behaviors but no differences in roadway, vehicle, and environmental factors. We also found that rental car crashes involve more males and drivers under 25 years of age.

\section{Introduction}

The car rental industry comprises an important part of the transport sector in many developed countries. In the United States, for example, there were about 2.2 million rental cars in 2015 , generating over $\$ 26$ billion in revenue for the industry [1]. In South Korea, the car rental market was worth an estimated 3.2 trillion won (US $\$ 3.1$ billion) while the car leasing market was worth about 5.9 trillion won (US\$5.7 billion) in 2013 [2]. Moreover, the global car rental industry had been forecasted to grow by 5.6 per cent from 2016 to 2021 [3].

The increase in the number of rental cars on the roads is expected to increase the number of traffic collisions involving these vehicles. More importantly, relative to private vehicles, rental cars have been found to experience a higher collision rate per registered vehicle and these collisions often result in higher injury severity [4]. Despite the importance of the rental car industry to the economy and its impact on traffic safety, few studies have been conducted to understand the factors associated with rental car crashes or the differences in the factors contributing to crashes involving rental cars and nonrental cars.

The objective of this study is to develop a conceptual framework and derive testable hypotheses to examine the differences in the factors contributing to crashes involving rental cars and nonrental cars. More specifically, it will examine the differences in risky driving behaviors and driver characteristics that contribute to crashes involving rental cars and nonrental cars.

\section{Conceptual Framework and Hypotheses}

There are many reasons why rental car crashes may be different from privately owned or nonrental car crashes. This study will focus on three possible driver-related explanations for which data are available to test the related hypotheses generated. Other factors, such as age and safety features of the vehicles, are beyond the scope of this paper because the data needed to test these influences are not available.

The first driver-related reason considered in this study is the lower familiarity with the car and the road environment. Since the driver does not own the vehicle, he or she may not be familiar with the handling and performance of the vehicle. Also, since rental cars are often operated by out-of-town drivers on business or holiday trips, these drivers may be less familiar with the road and driving environment. This lack of familiarity with the car and the environment may contribute to more driving errors (poor handling, poor judgement, etc.) 
but not necessarily more risk-taking behaviors (aggressive driving, inattention, etc.). On the contrary, it may also result in more cautious behaviors by some drivers who may compensate for the increased risk due to the lack of familiarity. For example, Yanko and Spalek [5] found that route familiarity led to more inattention and Rosenbloom et al. [6] found that drivers committed more violations and exhibited more dangerous behaviors in well-known locations compared to less known locations.

The second possible reason is the differences in driver demography. In one of the very few studies that examined crash rates of rental cars and privately owned cars, AlBalbissi [4] found that rental cars had a higher crash rate per registered vehicle in Jordan. Using a driver questionnaire survey, they found that rental car drivers were generally younger in age and had fewer years of driving experience compared to drivers of privately owned cars. However, the survey did not include any item on risky driving behaviors or provide any evidence that rental cars and privately owned cars drivers behaved differently. Nevertheless, numerous studies had found that younger drivers, especially young males, tended to take more risks $[7,8]$.

The third explanation is the difference in vehicle ownership. Since most drivers of rental cars do not own the vehicles or lease the vehicles for a very long time, they may have little attachment to the vehicles and thus have lower emotional costs if their vehicles are damaged in collisions. Additionally, some of the rental car drivers may also have lower financial costs associated with any risky behaviors and potential crashes because they may not be responsible for the repairs or replacement costs due to separate insurance coverage. Additionally, the expected crash cost may also be lower due to smaller disruptions to their travel routines if their rental vehicles are damaged. In short, the nonownership of the vehicle may result in the classical moral hazard problem and encourage drivers of rental cars to take more risks and thus experience higher crash rates [9-12].

In summary, there are sufficient reasons to hypothesize that crashes involving rental cars may be associated with higher proportions of poor vehicle handling and risky driving behaviors. Additionally, crashes involving rental cars may also be associated with a higher proportion of younger and male drivers.

\section{Materials and Methods}

Similar to many traffic collision studies [13-16], this study uses a retrospective approach to identify the factors contributing to crashes. More specifically, this study will identify the differences in the factors associated with crashes involving rental cars and nonrental cars, with a special focus on the role of risky driving behaviors and demographic characteristics as crash contributing factors.

3.1. Data. The motor vehicle crash data used in this study was provided by the Korean National Police Agency. The data included information on drivers' age and gender and human related factors, as well as road, vehicle, and environmental factors. In 2010, there were 226,871 reported crashes, of which
158,189 crashes or 69.73 per cent involved at one least rental car or nonrental car. Of the 204,523 cars involved in these crashes, 6,286 (3.1\%) were rental cars. Although rental (shortterm lease) cars were recorded using a unique category in the database, long-term lease vehicles were not separately identified. Hence, nonrental cars in this study would include both privately owned and long-term lease vehicles.

It should be noted that there were 257,000 registered rental cars in Korea in 2010 [17] and 6,286 rental cars were involved in crashes in 2010, giving an average of crash involvement rate of $2.45 \%$. Also, the share of rental cars among total registered passenger vehicles was only $1.9 \%$ in 2010 [17] but the share of rental cars among all cars involved in crashes was $3.1 \%$.

Since the objective of this study was to examine the differences in risky driving behaviors and driver characteristics that contribute to crashes involving rental cars and nonrental cars, the first group of explanatory variables examined included the different driving behaviors recorded in the police report under the "human-accident factor" section. As shown in Table 1, six semiaggregated variables were created by combining similar categories among the original 25 categories in the human-accident factors section of the police crash report.

Besides the above driver-related factors, the age and gender of the road users involved were also included. In addition, three aggregate variables were used to account for other nonhuman factors. These control variables were "no road factor," "no environmental factor," and "no vehicle factor." These variables represented the simplest and most informative variable for each of the three broad categories of contributing factors besides the road users.

3.2. Data Analyses. As an exploratory analysis, a series of $z$ tests were conducted to test for differences in risky driving behaviors recorded in the police crash reports between rental car drivers and nonrental car drivers. Although the $z$-test would be a simple and straightforward method to test for these differences, this method would ignore any correlations among the independent variables. It also would not provide any estimates of the relative weights or the influence of the variables.

To obtain estimates of the partial effects of each behavior, holding other behaviors constant, a binary regression model was also estimated. The logistic regression model was widely used in road safety studies where the dependent variable was binary [18-22]. In this study, the binary response variable was defined as

$$
y_{n}= \begin{cases}1, & \text { if vehicle } n \text { is a rental car } \\ 0, & \text { if it is not a rental car. }\end{cases}
$$

Further, if a logistic distribution was used, then the probability of crash vehicle $n$ being a rental car would be given by

$$
P_{n}=\frac{\exp \left(\beta \mathbf{x}_{n}\right)}{1+\exp \left(\beta \mathbf{x}_{n}\right)},
$$


TABLE 1: Human related contributing factors.

\begin{tabular}{|c|c|}
\hline Variables & Original factors listed \\
\hline \multirow{4}{*}{ Aggressive driving } & Driving shape, sudden cut-in \\
\hline & Driving shape, competitive driving \\
\hline & Driving shape, threatening driving \\
\hline & Driving shape, weaving \\
\hline \multirow{5}{*}{ Poor driving } & Psychological factor, misunderstanding of opponent's behavior \\
\hline & Psychological factor, hurriedness \\
\hline & Psychological factor, poor driving \\
\hline & Psychological factor, misunderstanding of geographical information \\
\hline & Psychological factor, misunderstanding of surroundings \\
\hline \multirow{6}{*}{ Impaired driving } & Health condition, fatigue \\
\hline & Health condition, sickness \\
\hline & Health condition, physical disability \\
\hline & Health condition, drug effect \\
\hline & Health condition, drunken effect \\
\hline & Health condition, other poor mind and body conditions \\
\hline \multirow{5}{*}{ Inattention } & Front negligent gaze, doing another action \\
\hline & Front negligent gaze, carelessness \\
\hline & Front negligent gaze, drowsiness \\
\hline & Front negligent gaze, using cell phone \\
\hline & Front negligent gaze, other front negligent gaze instances \\
\hline \multirow{3}{*}{ Poor handling } & Poor handling, sudden braking \\
\hline & Poor handing, sudden steering \\
\hline & Poor handling, other \\
\hline Other & Other human factors \\
\hline
\end{tabular}

where

$\mathbf{x}_{n}$ would be a vector of crash characteristics;

$\beta$ would be a vector of parameters to be estimated.

The best estimate of $\beta$ could be obtained by maximizing the log-likelihood function:

$$
\operatorname{LL}(\boldsymbol{\beta})=\sum_{i=1}^{n}\left\{y_{i n} \ln \left(P_{n}\right)+\left(1-y_{\text {in }}\right) \ln \left(1-P_{n}\right)\right\}
$$

The maximum likelihood estimator obtained would be consistent and asymptotically efficient since the observations were selected randomly $[23,24]$. The standard logistic model was estimated using Stata version 14

However, since the share of rental cars in the sample was very small (3.1\%), the standard logistic model might produce biased and inconsistent results. Hence, the rare event logistics and the Firth logistic model were also estimated. The rare event logistic model utilized choice-based sampling where all observations for which $Y=1$ were selected and only a sample of $Y=0$ was selected. A weighted sampling maximum likelihood estimator would then be used $[25,26]$. In this study, the statistical software, RELogit, is used for model development and estimation. This freely available software was developed by Tomz et al. [27] and King and Zeng [28, 29] and can be used in the Stata program.
An alternative method to address the possible bias in the standard logistic regression model would be to use a different estimation method proposed by Firth [30]. The Firth logistic model utilized a penalized maximum likelihood method and used Jeffreys' [31] invariant prior as a bias reducing penalty function. In this study, the statistical software, FirthLogit, is used for model development and estimation. This freely available software was developed by Coveney [32] and can be used in the Stata program.

Note that some researchers chose to use the random coefficient logit or probit model to allow for heterogeneous effects and correlations in unobserved factors [33-36]. Random parameters models, especially the random parameter logit or mixed logit model, had increasingly been used in traffic safety studies to analyze both crash frequency and severity [37-40]. In random parameter model, to let parameter $\left(\beta_{i}\right)$ vary across observations, a mixing distribution is added [41]:

$$
P_{\text {in }}=\int \frac{\exp \left[\beta_{i} X_{\text {in }}\right]}{\sum_{I} \exp \left[\beta_{i} X_{\text {in }}\right]} f\left(\beta_{i} \mid \varphi\right) d \beta_{i},
$$

where $f\left(\beta_{i} \mid \varphi\right)$ is the density function of $\beta$ and $\varphi$ refers to a vector of parameters of the density function and other terms are as previously defined. The above model is usually estimated using the simulation of maximum likelihood with Halton draws [42, 43].

Several distributions had been considered in the literature, including normal, uniform, and lognormal ones. 
TABLE 2: Summary of variables by vehicle ownership.

\begin{tabular}{|c|c|c|c|c|}
\hline Variables & Rental & Nonrental & $z$-stat. & $p$ value \\
\hline \multicolumn{5}{|c|}{ Driver demographic characteristics } \\
\hline Male ${ }^{* * *}$ & 0.8664 & 0.6911 & 29.761 & $<0.001$ \\
\hline Age under $25^{* * *}$ & 0.1802 & 0.0627 & 37.014 & $<0.001$ \\
\hline Age $25-44^{* * *}$ & 0.5508 & 0.5729 & 3.468 & 0.001 \\
\hline Age $45-64^{* * *}$ & 0.2326 & 0.3351 & 16.990 & $<0.001$ \\
\hline Age 65 and over*** & 0.0143 & 0.0515 & 13.279 & $<0.001$ \\
\hline \multicolumn{5}{|l|}{ Driver behaviors } \\
\hline Inattention $^{* * *}$ & 0.4469 & 0.4126 & 5.436 & $<0.001$ \\
\hline Impaired driving & 0.0754 & 0.0756 & -0.059 & 0.953 \\
\hline Poor driving*** & 0.0436 & 0.0330 & 4.608 & $<0.001$ \\
\hline Poor handling*** & 0.0124 & 0.0089 & 2.893 & $<0.001$ \\
\hline Aggressive driving ${ }^{* * *}$ & 0.0068 & 0.0041 & 3.248 & $<0.001$ \\
\hline Other driver factors & 0.0255 & 0.0263 & -0.391 & 0.696 \\
\hline No driver factor ${ }^{* * *}$ & 0.3837 & 0.4340 & -7.930 & $<0.001$ \\
\hline \multicolumn{5}{|l|}{ Control variables } \\
\hline No vehicle factor & 0.9753 & 0.9726 & 1.294 & 0.196 \\
\hline No road factor & 0.9583 & 0.9615 & 1.297 & 0.195 \\
\hline No environmental factor & 0.9943 & 0.9946 & 0.320 & 0.626 \\
\hline
\end{tabular}

Note. Means or proportions reported; $* * *$ denotes statistical significance at $99 \%$ confidence level.

Although the normal distribution has been widely used in road safety research, Hensher and Greene [44] and Train [41] suggested that the normal distribution should be used for continuous variables while the uniform distribution should be used for dummy or binary variables. Therefore, the uniform distribution was used as a density function in this study. The random parameters logit model was estimated using NLogit version 5 . In this software, the scale parameter obtained would be half the range of the uniform distribution.

\section{Results and Discussion}

As shown in Table 2, the difference in the means or proportions of crashes involving rental cars and nonrental cars that had no driver-related crash factor was found to be statistically significant $(z=-7.930 ; p<0.001)$, with a lower mean for rental cars $(\mathrm{M} 1=0.3837)$ than for nonrental cars $(\mathrm{M} 2=0.4340)$. More specifically, more drivers of rental cars exhibited inattention $(\mathrm{M} 1=0.4469 ; \mathrm{M} 2=0.4126 ; z=5.436$; $p<0.001)$, poor driving ( $\mathrm{M} 1=0.0436 ; \mathrm{M} 2=0.0330 ; z=$ 4.608; $p<0.001)$, poor vehicle handling $(\mathrm{M} 1=0.0124 ; \mathrm{M} 2=$ $0.0089 ; z=2.893 ; p<0.001)$, and aggressive driving $(\mathrm{M} 1=$ $0.0068 ; \mathrm{M} 2=0.0041 ; z=3.248 ; p<0.001)$ than drivers of nonrental cars. These results implied that a greater proportion of drivers of rental cars were considered to have contributed to the crash by their poor or risky driving behaviors. This result was generally consistent with our proposed hypotheses.

As shown in Table 2, the proportion of male drivers involved in rental car crashes was higher than the corresponding proportion in nonrental cars $(\mathrm{M} 1=0.8664 ; \mathrm{M} 2$ $=0.6911 ; z=29.761 ; p<0.001)$. Also, as expected, the proportion of drivers under 25 years old involved in rental car crashes was higher than the corresponding proportion in nonrental cars $(\mathrm{M} 1=0.1802 ; \mathrm{M} 2=0.0627 ; z=37.014 ; p<$ $0.001)$. These results implied that a greater proportion of the drivers of rental cars who were involved in crashes consisted of younger and male drivers compared to crashes involving nonrental cars. These results provided some support for our proposed hypotheses.

Besides the simple $z$-test, a binary regression model, rare event logistic model, and a Firth logistic model were also estimated to obtain the estimates of the partial effects of each behavior, holding other behaviors constant. As shown in Table 3, the results of the three models were very similar, with very similar goodness-of-fit statistics, as well as very similar coefficient estimates. In terms of goodness of fit, the estimated log-likelihood value was -26938.4 for the standard binary logistic model and -26898.9 for the Firth logistic model, indicating that the Firth logistic model had a slightly better fit. The consistency in the results obtained for the three models could be explained by the very large sample size $(204,523)$ and the number of observations for rental cars (6286), even though its share was extremely small (3.1\%). Nevertheless, it was vital to confirm that the small share of tourist routes did not create any estimation problem.

In addition to three fixed parameters models, a random parameter logit model was also estimated to account for unobserved heterogeneity in the observations. In terms of goodness of fit, the estimated log-likelihood value was -26931.4 , which was slightly higher than the corresponding value of -26938.4 for the standard binary logistic model but slightly lower than the estimated value of -26898.9 for the Firth logistic model. However, many scale parameters for the coefficients were found to be statistically significant. Hence, 


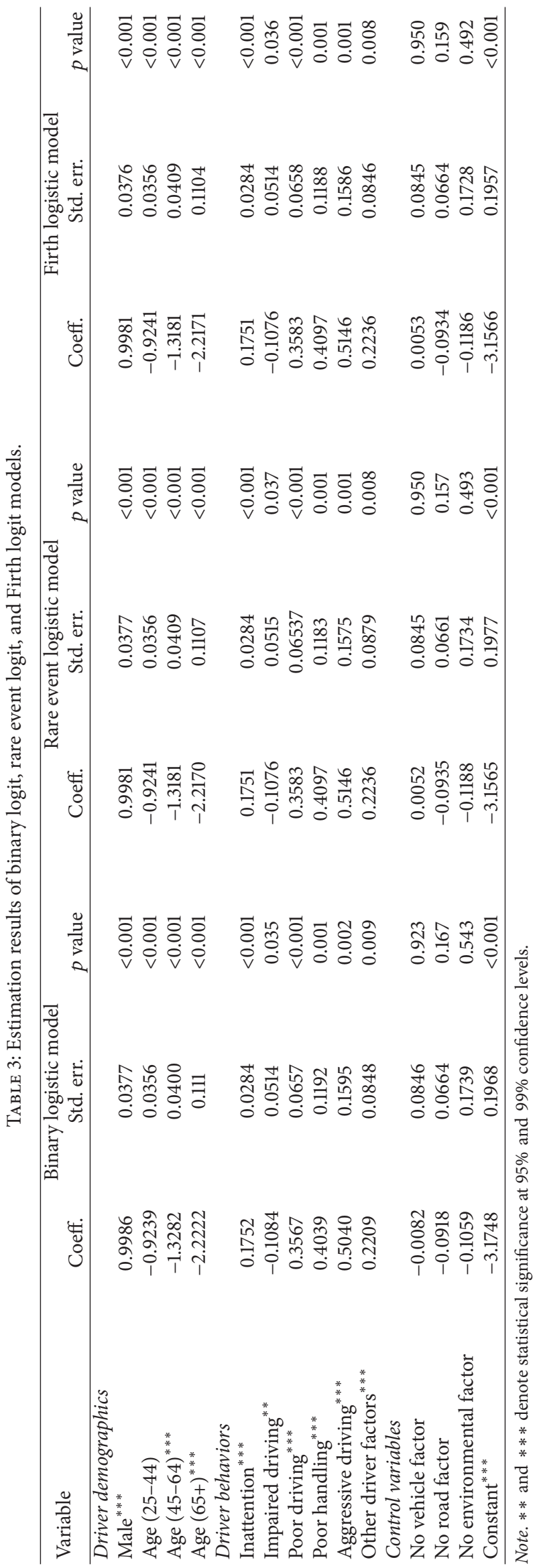


TABLE 4: Estimation results of random parameters binary logit model.

\begin{tabular}{|c|c|c|c|c|c|c|}
\hline \multirow{2}{*}{ Variable } & \multicolumn{3}{|c|}{ Mean } & \multicolumn{3}{|c|}{ Scale } \\
\hline & Coeff. & Std. err. & $p$ value & Coeff. & Std. err. & $p$ value \\
\hline \multicolumn{7}{|l|}{ Driver demographics } \\
\hline Male & $0.7057^{* * *}$ & 0.0268 & $<0.001$ & $0.2322^{* * *}$ & 0.024 & $<0.001$ \\
\hline Age (25-44) & $-0.6718^{* * *}$ & 0.0256 & $<0.001$ & $0.2499^{* * *}$ & 0.023 & $<0.001$ \\
\hline Age (45-64) & $-0.9469^{* * *}$ & 0.0294 & $<0.001$ & $0.0979^{* *}$ & 0.046 & 0.034 \\
\hline Age (65+) & $-1.8044^{* * *}$ & 0.1010 & $<0.001$ & $1.4224^{* * *}$ & 0.218 & $<0.001$ \\
\hline \multicolumn{7}{|l|}{ Driver behaviors } \\
\hline Inattention & $0.1241^{* * *}$ & 0.0202 & $<0.001$ & 0.0366 & 0.034 & 0.276 \\
\hline Impaired driving & $-0.4158^{* * *}$ & 0.0514 & $<0.001$ & $1.8590^{* * *}$ & 0.107 & $<0.001$ \\
\hline Poor driving & $0.2182^{* * *}$ & 0.0491 & $<0.001$ & $0.5955^{* * *}$ & 0.113 & $<0.001$ \\
\hline Poor handling & 0.0204 & 0.1156 & 0.860 & $1.6644^{* * *}$ & 0.257 & $<0.001$ \\
\hline Aggressive driving & $0.3588^{* * *}$ & 0.1153 & 0.002 & 0.1020 & 0.281 & 0.716 \\
\hline Other driver factors & $-0.1387^{*}$ & 0.0834 & 0.096 & $1.7362^{* * *}$ & 0.179 & $<0.001$ \\
\hline \multicolumn{7}{|l|}{ Control variables } \\
\hline No vehicle factor & -0.3231 & 0.0605 & 0.593 & $0.6219^{* * *}$ & 0.023 & $<0.001$ \\
\hline No road factor & $-0.0856^{*}$ & 0.0477 & 0.072 & $0.4361^{* * *}$ & 0.023 & $<0.001$ \\
\hline No env. factor & -0.0747 & 0.1239 & 0.546 & $0.0670^{* * *}$ & 0.023 & 0.003 \\
\hline Constant & $-2.2427^{* * *}$ & 0.1392 & $<0.001$ & - & - & - \\
\hline
\end{tabular}

Note. $*, * *$, and $* * *$ denote statistical significance at $90 \%, 95 \%$, and $99 \%$ confidence levels.

the random coefficient logistic model could be considered as the preferred model and the results of this model would be used for further discussion on the influences of crash factors.

As shown in Table 4, the estimated coefficient of the mean effect of "male" was positive and statistically significant, indicating that male drivers were more likely than female drivers to be associated with rental car crashes than nonrental car crashes. Also, since the estimate of the scale parameter was less than the mean, the entire range of the uniform distribution was positive, implying that the positive effect was applicable to all observations. Additionally, the estimated coefficients of the three older aged groups (25-44, 45-64, and 65+) were negative and statistically significant, indicating that, relative to drivers under 25 years old, older drivers were less likely to be involved in rental car crashes. Again, since the estimates of all the scale parameters were smaller in magnitude than the mean, the negative correlation would hold for all observations. These results confirmed our hypotheses that rental car crashes would have a higher proportion of young male drivers than nonrental car crashes. These results were also consistent with the findings of Al-Balbissi [4].

With respect to the driver-related factors, two results from Table 4 were different from those reported in Table 2. First, "other driver factors" was not found to be statistically significant in the simple $z$-test but was found to be marginally statistically significant at the $90 \%$ confidence level in the random parameter logit model. Second, impaired driving was found to be statistically insignificant in the simple $z$-test but was found to be associated more with nonrental cars than with rental cars in the regression models.

Overall, four of six risky behaviors were found to be associated more with rental cars than with nonrental cars, and three of these behaviors were statistically significant at the traditional 95\% confidence level, while poor handling was not statistically significant, even at the $90 \%$ confidence level. The estimates for inattention, aggressive driving, and poor driving were positive and significant, indicating that these poor and risky behaviors were associated more with rental car drivers than with nonrental car drivers.

It should be noted that four of the six estimates of the scale parameters were relatively large compared to the estimated magnitude of the means, implying that there were significant variations in the effects of driver behavior across the observations. For example, the estimated mean and scale parameter of impaired driving were -0.4158 and 1.8590 , respectively, implying that the effect of impaired driving was positive for about $38.8 \%$ of the sample although the overall effect was negative. Similarly, the estimated mean and scale parameter of other driving factors were -0.1387 and 1.7362 , respectively, implying that the effect of other driving factors was positive for about $46.0 \%$ of the sample although the overall effect was negative.

In general, the results on driver behaviors reported above implied that, with the exception of impaired driving, a greater proportion of drivers of rental cars were considered to have contributed to the crash by their poor or risky driving behaviors, such as poor driving, inattention, and aggressive driving. These results provided some support for our proposed hypotheses. However, the insignificance of poor handling and the significance of more risk-taking behaviors, such as aggressive driving and inattention, implied that the differences in behavior were due to more than just unfamiliarity with the vehicle and environment. These results could be better explained by the greater risk-taking propensity among younger drivers $[7,8]$ and the economic principle of moral hazard [9-12]. 
To reduce the likelihood of crashes involving rental cars due to unfamiliarity with the environment, rental car companies could equip more of their cars with advanced traveler information systems and transportation departments could conduct a review of traffic control and signage, especially informational signs, to ensure that they provide better information and directions to visitors. To address the issues related to risk taking and moral hazard, policymakers responsible for rental car safety, rental car regulation, or rental car operations should consider measures to reduce this market inefficiency and improve the safety of all road users. Examples of such measures would be to provide proper incentives for safe driving behavior or adequate disincentives for risky driving behavior in the rental car lease, including penalties for risky driving or rewards for safe driving, such as differential insurance, rental rates, or the use of refundable safety deposits.

\section{Conclusions}

Despite its importance in the transport sector in many developed countries, the safety of rental cars has received relatively little attention in the transportation safety literature. This study proposes three driver-related reasons to support the hypotheses that rental car crashes may involve a greater proportion of young male drivers and greater proportions of drivers who exhibit poor and risky driving behaviors.

To test these hypotheses, this study compares the factors contributing to crashes involving rental cars and nonrental cars in South Korea using the standard binary logistics, rare event logistics, Firth logistics, and random parameters logistic models. We found a significantly higher contribution of poor or risky driving behaviors in rental cars than in nonrental cars, but little or no difference in roadway, vehicle, and environmental factors. We also found that rental car crashes involve more male and younger (under 25) drivers. These results provide some support for the hypotheses developed.

It should be noted that the objective of this study is to develop a conceptual framework and derive testable hypotheses to examine the differences in the factors contributing to crashes involving rental cars and nonrental cars, with a focus on the differences in risky driving behaviors, and to test the hypotheses using data from Korea. Further research should be conducted to extend the conceptual framework to capture the effect of rental cars on crash and driver injury severity and test the extended framework using different statistical models, such as the nested logit model or bivariate logit model, with different model specifications to account for potential confounding, mediating, and moderating effects.

\section{Conflicts of Interest}

The authors declare that there are no conflicts of interest regarding the publication of this paper.

\section{References}

[1] Auto Rental News, "Fact sheet 2016: 2015 U.S. car rental market," 2016, http://www.autorentalnews.com/fileviewer/2229.aspx.
[2] K. Joo, "Renting or leasing cars is accelerating big time," Korea Joongang Daily, September 2014.

[3] Research and Markets, "The global car rental industry 2016-2021,” 2016, http://www.researchandmarkets.com/reports/ 3619429/the-global-car-rental-industry-2016-2021-trends.

[4] A. H. Al-Balbissi, "Unique accident trend of rental cars," Journal of Transportation Engineering, vol. 127, no. 2, pp. 175-177, 2001.

[5] M. R. Yanko and T. M. Spalek, "Route familiarity breeds inattention: a driving simulator study," Accident Analysis and Prevention, vol. 57, pp. 80-86, 2013.

[6] T. Rosenbloom, A. Perlman, and A. Shahar, "Women drivers' behavior in well-known versus less familiar locations," Journal of Safety Research, vol. 38, no. 3, pp. 283-288, 2007.

[7] P. Ulleberg and T. Rundmo, "Personality, attitudes and risk perception as predictors of risky driving behaviour among young drivers," Safety Science, vol. 41, no. 5, pp. 427-443, 2003.

[8] R. Tay, "The effectiveness of enforcement and publicity campaigns on serious crashes involving young male drivers: are drink driving and speeding similar?" Accident Analysis and Prevention, vol. 37, no. 5, pp. 922-929, 2005.

[9] H. Schneider, "Moral hazard in leasing contracts: evidence from the New York city taxi industry," Journal of Law and Economics, vol. 53, no. 4, pp. 783-805, 2010.

[10] C. K. Jackson and H. S. Schneider, "Do social connections reduce moral hazard? Evidence from the New York City taxi industry," American Economic Journal: Applied Economics, vol. 3, no. 3, pp. 244-267, 2011.

[11] D. E. Cantor, H. Celebi, T. M. Corsi, and C. M. Grimm, "Do owner-operators pose a safety risk on the nation's highways?" Transportation Research Part E: Logistics and Transportation Review, vol. 59, pp. 34-47, 2013.

[12] R. Tay and J. Choi, "Factors associated with crashes involving taxi owners and non-owners: a case of moral hazard and adverse selection?" Accident Analysis and Prevention, vol. 87, pp. 78-82, 2016.

[13] S. Balakrishnan, S. Moridpour, and R. Tay, "Differences in single heavy vehicle crashes at intersections and midblocks," Journal of Advanced Transportation, vol. 50, no. 8, pp. 2150-2159, 2017.

[14] R. Tay, "Comparison of the binary logistic and skewed logistic (Scobit) models of injury severity in motor vehicle collisions," Accident Analysis and Prevention, vol. 88, pp. 52-55, 2016.

[15] R. Tay, "Speed cameras: improving safety or raising revenue?" Journal of Transport Economics and Policy, vol. 44, no. 2, pp. 247-257, 2010.

[16] U. Barua and R. Tay, "Severity of urban transit bus crashes in Bangladesh," Journal of Advanced Transportation, vol. 44, no. 1, pp. 34-41, 2010.

[17] KED, "No. of rental car users on the rise," Korean Economic Daily, September 2016.

[18] K. Haleem and M. Abdel-Aty, "Examining traffic crash injury severity at unsignalized intersections," Journal of Safety Research, vol. 41, no. 4, pp. 347-357, 2010.

[19] R. Tay, U. Barua, and L. Kattan, "Factors contributing to hitand-run in fatal crashes," Accident Analysis and Prevention, vol. 41, no. 2, pp. 227-233, 2009.

[20] R. Tay, S. M. Rifaat, and H. C. Chin, "A logistic model of the effects of roadway, environmental, vehicle, crash and driver characteristics on hit-and-run crashes," Accident Analysis and Prevention, vol. 40, no. 4, pp. 1330-1336, 2008.

[21] S. Anowar, S. Yasmin, and R. Tay, "Comparison of crashes during public holidays and regular weekends," Accident Analysis and Prevention, vol. 51, pp. 93-97, 2013. 
[22] S. M. Rifaat and R. Tay, "Effects of street patterns on injury risks in two-vehicle crashes," Transportation Research Record, vol. 2102, pp. 61-67, 2009.

[23] D. McFadden, "Econometric models of probabilistic choice," in A Structural Analysis of Discrete Data with Econometric Applications, C. Manski and D. McFadden, Eds., The MIT Press, Cambridge, Mass, USA, 1981.

[24] W. Greene, Econometric Analysis, Prentice Hall, New York, NY, USA, 2012.

[25] C. F. Manski and S. R. Lerman, "The estimation of choice probabilities from choice based samples," Econometrica, vol. 45, no. 8, pp. 1977-1988, 1977.

[26] G. King and L. Zeng, "Logistic regression in rare events data," Political Analysis, vol. 9, no. 2, pp. 137-163, 2001.

[27] M. Tomz, G. King, and L. Zeng, RELOGIT, Rare Events Logistic Regression, Version 1.1, Harvard University, Cambridge, Mass, USA, 1999, http://gking.harvard.edu/.

[28] G. King and L. Zeng, Logistic Regression in Rare Events Data, Department of Government, Harvard University, Cambridge, Mass, USA, 1999, http://GKing.Harvard.Edu.

[29] G. King and L. Zeng, Estimating Absolute, Relative, and Attributable Risks in Case-Control Studies, Department of Government, Harvard University, Cambridge, Mass, USA, 1999, http://GKing.Harvard.Edu.

[30] D. Firth, "Bias reduction of maximum likelihood estimates," Biometrika, vol. 80, no. 1, pp. 27-38, 1993.

[31] H. Jeffreys, "An invariant form for the prior probability in estimation problems," Proceedings of the Royal Society. London. Series A. Mathematical, Physical and Engineering Sciences, vol. 186, pp. 453-461, 1946.

[32] J. Coveney, "FIRTHLOGIT: stata module to calculate bias reduction in logistic regression," 2008, http://econpapers.repec .org/software/bocbocode/s456948.htm.

[33] J. C. Milton, V. N. Shankar, and F. L. Mannering, "Highway accident severities and the mixed logit model: an exploratory empirical analysis," Accident Analysis and Prevention, vol. 40, no. 1, pp. 260-266, 2008.

[34] J.-K. Kim, G. F. Ulfarssom, V. N. Shankar, and F. L. Mannering, "A note on modeling pedestrian-injury severity in motorvehicle crashes with the mixed logit model," Accident Analysis and Prevention, vol. 42, no. 6, pp. 1751-1758, 2010.

[35] R. Tay, "A random parameters probit model of urban and rural intersection crashes," Accident Analysis and Prevention, vol. 84, pp. 38-40, 2015.

[36] P. C. Anastasopoulos and F. L. Mannering, "An empirical assessment of fixed and random parameter logit models using crash- and non-crash-specific injury data," Accident Analysis and Prevention, vol. 43, no. 3, pp. 1140-1147, 2011.

[37] D. Lord and F. Mannering, "The statistical analysis of crashfrequency data: a review and assessment of methodological alternatives," Transportation Research A: Policy and Practice, vol. 44, no. 5, pp. 291-305, 2010.

[38] P. T. Savolainen, F. L. Mannering, D. Lord, and M. A. Quddus, "The statistical analysis of highway crash-injury severities: a review and assessment of methodological alternatives," Accident Analysis \& Prevention, vol. 43, no. 5, pp. 1666-1676, 2011.

[39] N. S. Venkataraman, G. F. Ulfarsson, V. Shankar, J. Oh, and M. Park, "Model of relationship between interstate crash occurrence and geometrics," Transportation Research Record, vol. 2236, pp. 41-48, 2011.
[40] J.-K. Kim, G. F. Ulfarsson, S. Kim, and V. N. Shankar, "Driverinjury severity in single-vehicle crashes in California: a mixed logit analysis of heterogeneity due to age and gender," Accident Analysis and Prevention, vol. 50, pp. 1073-1081, 2013.

[41] K. E. Train, Discrete Choice Methods with Simulation, Cambridge University Press, Cambridge, UK, 2003.

[42] K. Train, Halton Sequences for Mixed Logit. Technical Paper, Department of Economics, University of California, Berkeley, Calif, USA, 1999.

[43] C. R. Bhat, "Simulation estimation of mixed discrete choice models using randomized and scrambled Halton sequences," Transportation Research B: Methodological, vol. 37, no. 9, pp. 837-855, 2003.

[44] D. A. Hensher and W. H. Greene, "The mixed logit model: the state of practice," Transportation, vol. 30, no. 2, pp. 133-176, 2003. 


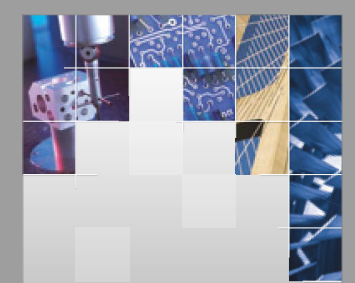

\section{Enfincering}
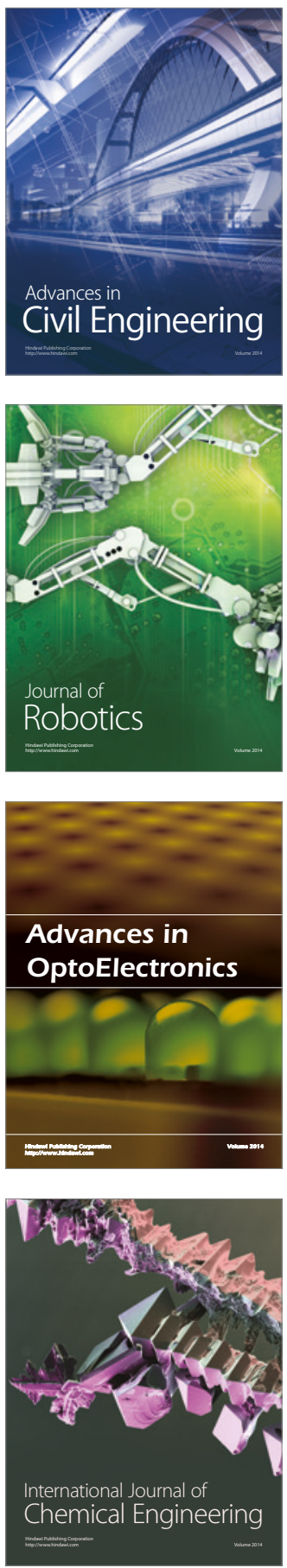

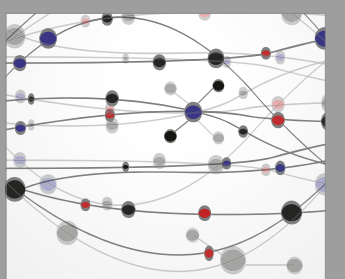

The Scientific World Journal

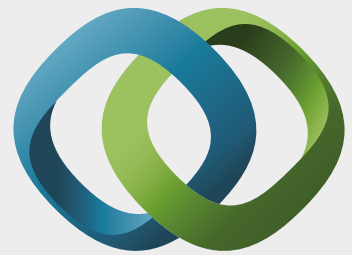

\section{Hindawi}

Submit your manuscripts at

https://www.hindawi.com
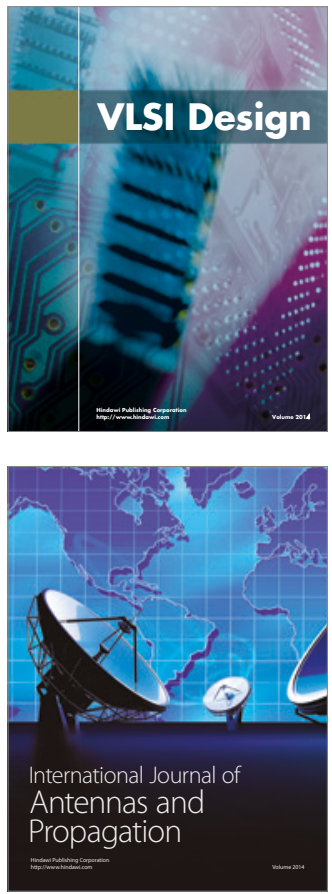

\section{Rotating}

Machinery
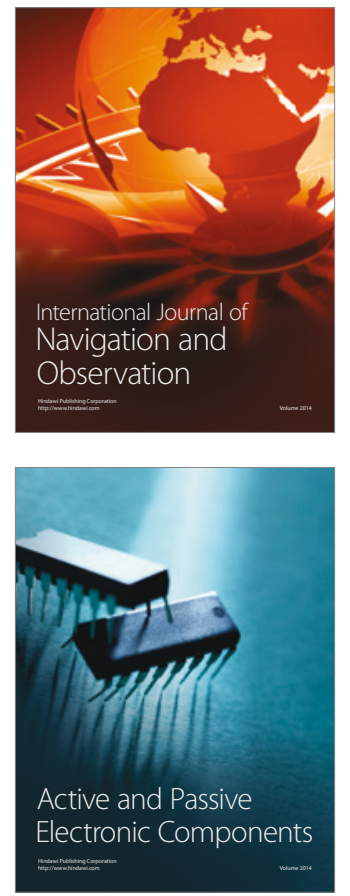
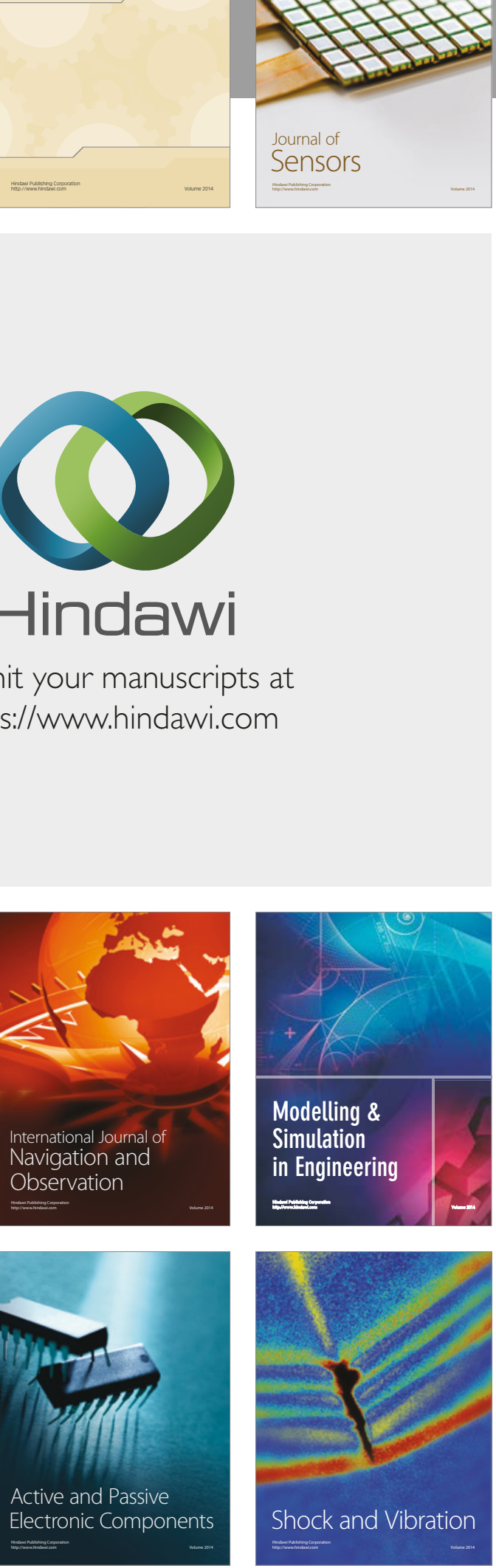
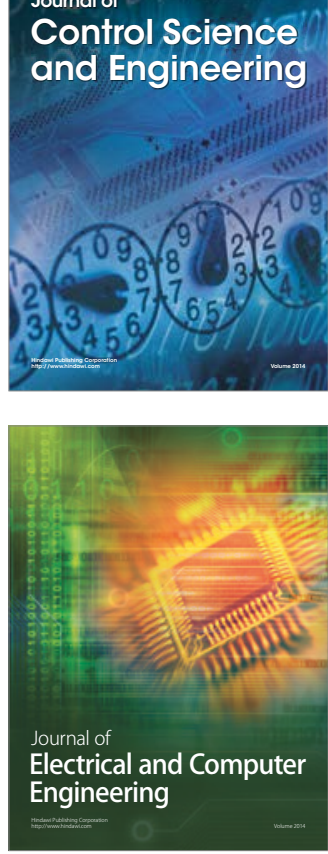

Distributed

Journal of

Control Science

and Engineering
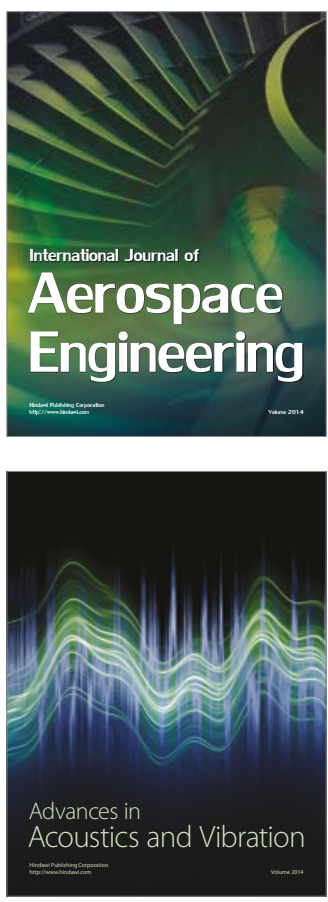

Sensor Networks 